\title{
New-onset atrial fibrillation can be falsely associated with increased length of stay in ICU due to immortal time bias
}

\author{
Yifang Lu' and Tenggao Chen ${ }^{2^{*}}$
}

Dear editor,

In a recent study published in Critical Care, Fernando SM and colleagues investigated the impact of new-onset atrial fibrillation (NOAF) on clinical outcomes in critically ill patients [1]. They performed univariate analysis and found that the length of stays (LOS) in ICU and hospital was both longer in the NOAF group versus non-NOAF group. They then concluded that NOAF was associated with increased LOS in ICU and increased total costs. While the conclusion appeared intuitive and statistically sound, it could be the result of immortal time bias. Immortal time is a span of cohort follow-up during which, because of exposure definition, the outcome under study could not occur [2]. The NOAF can happen at any time during ICU stay and patients live longer in the ICU can have more chance to report NOAF. For example, a patient can have NOAF on day 4 and the outcome such as ICU discharge or death cannot happen before day 4 . In this situation, the period from days 1 to 3 are considered as immortal time because if the outcome happens during the period, the patient cannot experience NOAF. The immortal time is incorrectly attributed to the exposure of NOAF, but actually, the NOAF do not contribute to the survival time. The same applies to the mortality outcome. The authors used binary logistic regression model to adjust for confounding effect and found there was no independent association of NOAF and mortality [3]. The truth could be that NOAF is associated with increased mortality risk, but since patients who lived longer can have more chances to experience NOAF, the neural effect reported in the paper was actually the result of the true adverse effect and the bias towards beneficial effect. Potential solutions to control for the immortal time bias are as follows: (1) perform analysis by restricting to patients who had NOAF on day 1 and compare to those without NOAF, (2) consider the time of NOAF and include NOAF as timevarying covariate in the Cox proportional hazard model [4], and (3) perform time-dependent propensity score matching by including covariates that can influence the onset of NOAF [5].

\section{Authors' response \\ Shannon M. Fernando, Rebecca Mathew, Benjamin Hibbert, Bram Rochwerg, Laveena Munshi, Allan J. Walkey, Morten Hylander Møller, Trevor Simard, Pietro Di Santo, F. Daniel Ramirez, Peter Tanuseputro and \\ Kwadwo Kyeremanteng}

The authors would like to thank Drs. Lu and Chen for their comments on our recent article related to outcomes and costs associated with new-onset atrial fibrillation (NOAF) in critically ill adults [1]. Drs. Lu and Chen suggest caution in the interpretation of

\footnotetext{
* Correspondence: chtgao@wmu.edu.cn

This comment refers to the article available at https://doi.org/10.1186/ s13054-020-2730-0.

2Department of colorectal surgery, Affiliated Dongyang Hospital of Wenzhou

Medical University, Dongyang, Zhejiang, People's Republic of China

Full list of author information is available at the end of the article
}

our study results, particularly as they relate to the length of stay and costs, due to the possibility of immortal time bias. Indeed, the use of time-dependent covariates (such as NOAF) has the potential to confound multivariate models [2]. However, as seen in our original study, the majority of patients who developed NOAF did so on the first day of hospital admission, consistent with previous studies in this 
population [6, 7]. As suggested by Drs. Lu and Chen, we conducted sensitivity analyses of our data, restricting the NOAF population to only those who developed NOAF on the first day of hospital admission ( $n=962,62.4 \%$ of the original NOAF population). Indeed, our original results persist, with patients with developing NOAF on the first day of admission still experiencing prolonged hospital stay, as compared to patients who did not develop NOAF (Table 1). We similarly repeated our generalized linear model restricted to this select population, in order to determine if NOAF was still associated with total hospital costs (Table 2). We found that NOAF was indeed a predictor of total hospital costs, even when only considering patients who developed NOAF on the first day of admission. These findings support the notion that our results were not markedly influenced by immortal time bias.

Finally, we would like to clarify that total hospital costs are not inferred as a multiple of hospital length of stay, as Drs. Lu and Chen suggest. In fact, all direct costs are linked directly to the patient identification number, and while they may be associated with length of stay (e.g., a person who stays in hospital for a longer length of time is likely to have increased testing and therapies, translating to higher costs), they are not obtained through a multiplication of length of stay, but rather reflect the direct resource use for each individual patient [8].

Table 1 Outcomes of ICU patients with new-onset atrial fibrillation (NOAF) on the first day of admission and those without NOAF

\begin{tabular}{|c|c|c|c|c|}
\hline Characteristic & $\begin{array}{l}\text { New-onset } \\
\text { atrial } \\
\text { fibrillation } \\
\text { on day } 1 \\
(n=962)\end{array}$ & $\begin{array}{l}\text { No atrial } \\
\text { fibrillation } \\
(n=13,473)\end{array}$ & $\begin{array}{l}\text { Adjusted odds } \\
\text { ratioc }^{c}(95 \% \mathrm{Cl})\end{array}$ & $\begin{array}{l}P \\
\text { value }\end{array}$ \\
\hline $\begin{array}{l}\text { In-hospital mortality, } \\
n(\%)\end{array}$ & $367(38.1)$ & 4034 (29.9) & $1.03(0.95-1.11)$ & 0.34 \\
\hline $\begin{array}{l}\text { Persistent atrial } \\
\text { fibrillation, } n(\%)^{\mathrm{b}}\end{array}$ & $238(24.7)$ & - & & \\
\hline $\begin{array}{l}\text { ICU length of stay, } \\
\text { days, median (IQR) }\end{array}$ & $7(2-14)$ & $6(2-9)$ & & $<0.01$ \\
\hline $\begin{array}{l}\text { Hospital length of } \\
\text { stay, days, median } \\
\text { (IQR) }\end{array}$ & $14(6-27)$ & $12(4-25)$ & & $<0.001$ \\
\hline $\begin{array}{l}\text { Ventilator-free } \\
\text { days, } \\
\text { median (IQR) }\end{array}$ & $6(2-8)$ & $6(4-10)$ & & 0.08 \\
\hline
\end{tabular}

Abbreviations: ICU intensive care unit, IQR interquartile range ${ }^{a}$ Only includes patients surviving to discharge

${ }^{\mathrm{b}}$ Defined as the presence of any atrial fibrillation following $24 \mathrm{~h}$ of treatment

${ }^{\mathrm{c}}$ Ratio of NOAF to patients with no atrial fibrillation
Table 2 Generalized linear model with gamma distribution and log link for the total cost for patients with new-onset atrial fibrillation (NOAF) on the first day or admission and those without $\operatorname{NOAF}(n=14,435)$

\begin{tabular}{|c|c|c|c|}
\hline Variable & $\begin{array}{l}\text { Cost } \\
\text { ratio }\end{array}$ & $95 \% \mathrm{Cl}$ & $\begin{array}{l}P \\
\text { value }\end{array}$ \\
\hline Age (per 5 years) & 0.96 & $0.90-1.03$ & 0.07 \\
\hline Male gender & 1.01 & $0.88-1.12$ & 0.17 \\
\hline New-onset atrial fibrillation & 1.08 & $1.02-1.19$ & $<0.01$ \\
\hline MODS (per 1 point) & 0.96 & $0.91-0.98$ & $<0.01$ \\
\hline \multicolumn{4}{|l|}{ Comorbidities } \\
\hline Congestive heart failure & 0.96 & $0.87-1.06$ & 0.35 \\
\hline Peripheral vascular disease & 1.05 & $0.97-1.13$ & 0.22 \\
\hline Hypertension & 1.02 & $0.92-1.09$ & 0.66 \\
\hline Chronic obstructive pulmonary disease & 0.95 & $0.88-1.12$ & 0.59 \\
\hline Diabetes mellitus & 1.02 & $0.92-1.11$ & 0.47 \\
\hline Chronic kidney disease & 0.98 & $0.81-1.21$ & 0.42 \\
\hline Liver disease & 0.91 & $0.77-1.08$ & 0.31 \\
\hline Alcohol misuse & 1.02 & $0.95-1.08$ & 0.77 \\
\hline Elixhauser comorbidity score (per 1 point) & 0.99 & $0.90-1.07$ & 0.53 \\
\hline No CPR directive at ICU admission & 0.82 & $0.70-0.92$ & $<0.001$ \\
\hline \multicolumn{4}{|l|}{ Location prior to ICU admission } \\
\hline Emergency department & Ref & & \\
\hline Hospital wards & 1.04 & $0.87-1.20$ & 0.51 \\
\hline Operating room & 1.09 & $0.99-1.29$ & 0.06 \\
\hline Peripheral hospital & 0.93 & $0.79-1.06$ & 0.11 \\
\hline \multicolumn{4}{|l|}{ Most responsible diagnosis } \\
\hline Other & Ref & & \\
\hline Infection/sepsis & 1.06 & $0.89-1.20$ & 0.45 \\
\hline Respiratory failure & 1.91 & $1.29-2.41$ & $<0.001$ \\
\hline Trauma & 1.49 & $1.15-1.88$ & $<0.001$ \\
\hline Malignancy & 0.94 & $0.79-1.10$ & 0.38 \\
\hline Spontaneous intracranial hemorrhage & 2.19 & $1.71-2.60$ & $<0.001$ \\
\hline Stroke & 1.14 & $1.01-1.28$ & 0.04 \\
\hline Overdose/poisoning & 0.88 & $0.80-0.96$ & $<0.01$ \\
\hline Renal failure & 0.83 & $0.66-0.93$ & $<0.001$ \\
\hline Gastrointestinal bleeding & 1.12 & $0.97-1.20$ & 0.10 \\
\hline Congestive heart failure & 1.06 & $0.95-1.15$ & 0.39 \\
\hline Cardiac arrest & 1.13 & $0.89-1.23$ & 0.68 \\
\hline Seizures/status epilepticus & 1.19 & $1.01-1.40$ & 0.03 \\
\hline Diabetic ketoacidosis & 0.73 & $0.61-0.83$ & $<0.001$ \\
\hline In-hospital death & 0.63 & $0.56-0.69$ & $<0.001$ \\
\hline Length of stay (per 1 day) & 1.03 & $1.02-1.05$ & $<0.01$ \\
\hline Invasive mechanical ventilation & 1.25 & $1.16-1.35$ & $<0.001$ \\
\hline Renal replacement therapy & 1.09 & $1.02-1.14$ & $<0.01$ \\
\hline
\end{tabular}

Abbreviations: MODS Multiple Organ Dysfunction Score, ICU intensive care unit, $\mathrm{Cl}$ confidence interval, CPR cardiopulmonary resuscitation 


\section{Acknowledgements}

None

\section{Authors' contributions}

QJ conceived the idea and drafted the manuscript. WL helped interpret the results. Both authors read and approved the final manuscript.

\section{Funding}

No funding

\section{Availability of data and materials}

No data for the work

\section{Ethics approval and consent to participate}

Not applicable

\section{Consent for publication}

Not applicable

\section{Competing interests}

The authors declare that they have no competing interests.

\section{Author details}

'Department of oncology, Affiliated Dongyang Hospital of Wenzhou Medical University, Dongyang, Zhejiang, People's Republic of China. ${ }^{2}$ Department of colorectal surgery, Affiliated Dongyang Hospital of Wenzhou Medical

University, Dongyang, Zhejiang, People's Republic of China.

Received: 15 January 2020 Accepted: 30 January 2020

Published online: 06 February 2020

\section{References}

1. Fernando SM, Mathew R, Hibbert B, Rochwerg B, Munshi L, Walkey AJ, et al. New-onset atrial fibrillation and associated outcomes and resource use among critically ill adults—a multicenter retrospective cohort study. Crit Care. 2020;24:15.

2. Lévesque LE, Hanley JA, Kezouh A, Suissa S. Problem of immortal time bias in cohort studies: example using statins for preventing progression of diabetes. BMJ. 2010;340:b5087.

3. Zhang Z. Model building strategy for logistic regression: purposeful selection. Ann Transl Med. 2016;4:111.

4. Zhang Z, Reinikainen J, Adeleke KA, Pieterse ME, Groothuis-Oudshoorn CGM. Time-varying covariates and coefficients in cox regression models. Ann Transl Med. 2018:6:121.

5. Lu B. Propensity score matching with time-dependent covariates. Biometrics. 2005;61:721-8 John Wiley \& Sons, Ltd (10.1111).

6. Wetterslev M, Haase N, Hassager C, Belley-Cote EP, Mclntyre WF, An Y, Shen J, Cavalcanti AB, Zampieri FG, Guimaraes HP, et al. New-onset atrial fibrillation in adult critically ill patients: a scoping review. Intensive Care Med. 2019:45(7):928-38.

7. Moss TJ, Calland JF, Enfield KB, Gomez-Manjarres DC, Ruminski C, DiMarco $J P$, Lake DE, Moorman JR. New-onset atrial fibrillation in the critically ill. Crit Care Med. 2017:45(5):790-7.

8. Fernando SM, Reardon PM, Dowlatshahi D, English SW, Thavorn K, Tanuseputro P, Perry JJ, Rosenberg E, Wijdicks EF, Heyland DK, et al. Outcomes and costs of patients admitted to the ICU due to spontaneous intracranial hemorrhage. Crit Care Med. 2018;46(5):e395-403.

\section{Publisher's Note}

Springer Nature remains neutral with regard to jurisdictional claims in published maps and institutional affiliations. 